\title{
Review on Effect of Fillers on Strength and Durability of Concrete
}

\author{
Nayan Kawaduji Mohankar*, Shrikant Solanke \\ Department of Civil Engineering, G. H. Raisoni College of Engineering, Nagpur, Maharashtra, India
}

\begin{abstract}
Industrial waste productions are increased these days, which is causing grief to the environment. Hence it is necessary to cut down the waste generation or reuse the waste. It is needed to utilize the waste to reduce environment damage. It is known that ashes produced from the industries can be used in construction. Ashes like fly ash can successfully replaces the cement showing good results. Researchers are finding the new ways to use ashes in production of cement. Now a days cement manufactures adulterates the cement with pozzolanic material like fly ash, rice husk ash, sugarcane bagasse ash etc. Using these product in concrete, they not only reduces the pollution but also lower the price effectively. If these fillers added in proportion it enhances the properties of concrete like workability, strength, water absorption, permeability etc. considerably. This review paper represents the properties of concrete when cement gets partially replaced by sugarcane bagasse ash, fly ash and rice husk ash. This paper primarily concentrates on the properties like durability and strength when cement concrete contain fillers in it. It also considers the non-destructive tests which are performed.
\end{abstract}

Keywords : Cement, Pozzolanic Materials, Partial Replacement, Durability Test, Non-Destructive Tests

\section{INTRODUCTION}

Cement is one of the most utilized material on earth. Concrete opposes enduring activity, substance assault, and scraped spot while keeping up its ideal designing properties. Various cements require various degrees of toughness relying upon the presentation condition and the properties wanted. Solid fixings, their proportioning, associations between them, setting and restoring rehearses, and the administration condition decide a definitive toughness and life of the concrete. The configuration administration life of most structures is regularly 30 years, in spite of the fact that structures frequently last 50 to 100 years or more. In view of their sturdiness, most concrete and stone work structures are obliterated because of utilitarian oldness as opposed to weakening. In any case, a solid shell or structure can be repurposed if a structure use or capacity changes or when a structure inside is remodelled. Concrete, as an auxiliary material and as the structure outside skin, can withstand nature's ordinary decaying systems just as catastrophic events.

Now a days researchers are taking interest in identifying the waste material from the industries which can be used in cement so to create eco-friendly concrete, these materials not only enhances the properties in concrete but also restricts the pollution which were caused by them if they are not used. These materials are also known as pozzolanic materials. These shows very good result when added in proportion, this paper focus primarily on the durability property. Durability is the resistance against weathering actions, corrosion, abrasion, chemical action, etc. and protecting the engineering wealth of the concrete. Some of these pozzolanic 
materials are fly ash, rice husk ash, sugarcane bagasse ash.

Fly ash is used vastly now a days in cement industry, it is recognised as one of the best replacement for cement. Fly ash is not only cost effective but also lower the cement content and rise the cement wealth. Fly ash also gives good workability and durability. On other side sugarcane bagasse ash and rice husk ash are obtained by burning sugarcane bagasse and husk obtained as a by-product from rice respectively. They also provide good strength if added in proper proportion in concrete mix. They also provides good resistance against chemical attack like sulphate, unlike fly ash they are less popular. This paper is an attempt to find the behaviour of cement when it gets partially replaced by these fillers.

\section{LITRATURE REVIEW}

Vinny et.al (2017) told that durability of concrete made with bagasse ash cement under sulphate and acid attack is higher to that of conventional concrete. The improvement in sulphate resistance is attributed to the consumption of calcium hydroxide in the pozzolanic reaction which prevented the formation of gypsum. The ideology of using waste ash was not only to reduce cost but also enhancing the properties of concrete, especially the durability and protection from habitat. So bagasse ash shows considerable effect.

Wankhede et.al (2014) experimentally studied that the exploration finishes up the examination on the impact of fly fiery debris on the properties of concrete for ostensible blend of M25 evaluation of cement. Droop loss of solid increments with increment in w/c proportion of concrete. For w/c proportion 0.35 with no admixtures, introductory droop can't be estimated by droop cone test as it is less. Extreme compressive quality of cement continues diminishing with increment in w/c proportion of cement. Droop loss of cement continues expanding with increment of amount of fly fiery remains. Concrete with $10 \%$ and $20 \%$ supplanting of bond with fly slag demonstrates great compressive quality for 28 days than ordinary cement for $0.35 \mathrm{w} / \mathrm{c}$ proportion. Yet, on account of $30 \%$ supplanting of bond with fly fiery remains extreme compressive quality of solid declines.

Siddamreddy et.al (2015) concluded that the Consistency of bond relies on its fineness. Fly fiery debris is having more noteworthy fineness than bond so the consistency increments incredibly, when fly powder rate increments. The ordinary consistency increments about $40 \%$ when fly fiery remains rate increments from $0 \%$ to $20 \%$ and usefulness was additionally expanded The ideal 7 and 28-day compressive quality have been gotten in the scope of $20 \%$ fly cinder substitution level. Increment in split elasticity past $20 \%$ fly ash substitution. Fly slag appears to have a more articulated impact on the flexural quality than the split elasticity. At the point when contrasted with other blend the misfortune in weight rate was observed to be diminished by 3.99 to 2.84. Furthermore, compressive quality was diminished when the bond was supplanted by $0 \%$ to $20 \%$ of fly powder.

Nasir et.al (2014) studied that from this test study it tends to be reasoned that: Inclusion of SCBA in cement in any case the substitution level essentially improved the sulphate obstruction of cement by decreasing the weight reduction and quality misfortune because of sulphate assault. The base weight reduction and quality misfortune got were $1.2 \%$ and $2.2 \%$ separately at $15 \%$ SCBA. The improvement in sulphate opposition can be credited to the utilization of portlandite in the pozzolanic response which avoided the development of gypsum.

Nithin et.al (2016) contemplated SCBA concrete performed better when contrasted with normal cement up to $10 \%$ substitution of sugar stick bagasse 
debris because of essence of high measure of silica in SCBA. Compressive quality was diminished when relieved in 5\% $\mathrm{MgSO} 4$ relatively when restored in typical water. It is seen that use of ash of sugarcane bagasse in solid aides in expanding the resistivity towards sulphate assault. The rate decrease in compressive quality was diminishing with increment in rate substitution of sugarcane bagasse debris when restored in 5\% $\mathrm{MgSO} 4$ which reasons that SCBA helps in opposing the solid towards sulphate assault.

Divyadevi et.al (2018) studied that different techniques for preparing and generation of SCBA mortar and cement could be reviewed. $45 \mu \mathrm{m}$ strainer gives the better pozzolanic movement. Consuming the material at $600-800^{\circ} \mathrm{C}$ and pounding for $120 \mathrm{~min}$ gives the $100 \%$ pozzolanic action. It could be finished up $20-30 \%$ of SCBA expands the mechanical and sturdiness properties. The halfway supplanting of concrete with SCBA lessens ecological issues, greenhouse gases and a worldwide temperature alteration.

Dabai et.al (2009) did investigation on rice husk fiery remains demonstrated high measure of silica for rice husk cinder (68.12\%) which is a generally excellent incentive for usefulness. The expansion in setting time of glue having rice husk fiery debris demonstrated low degree of hydration for rice husk powder solid which result from response among concrete and water, which free calcium hydroxide

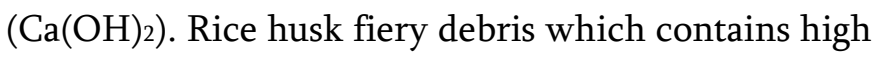
measure of silica, as in concrete, is significant as a minor bond substitute, if there is expansion of other crude materials containing somewhat higher calcium oxide and alumina.

Seyed et.al (2017) concluded that when rice husk ash is tested the sample of $25 \%$ RHA replacement shows minimum rate of chloride ion penetration. The $25 \%$ of RHA replacement also have less water absorption.
Rice husk debris as a pozzolanic responsive material can be utilized to improve surface zone of change zone between the infinitesimal structure of bond glue and total in the elite cement. It also increases almost $7 \%$ of compressive strength.

Ayesha et.al (2018) concluded that Adding RHA to the concrete the cohesiveness of the blend and builds its firmness as a result of the high fineness of RHA. It also shows the low slump, to keep up the usefulness, it is prescribed to utilize water lessening admixtures in RHA solid blends. It is clear that slump diminished with the expansion in RHA content.

Badorul et.al (2010) studied that diverse of rice husk debris at $0 \%, 10 \%, 20 \%, 30 \%$ and $40 \%$ replacement levels will be evaluate to decide the ideal of RHA in cement blends. The ideal crushing time of RHA likewise will be assessed. On the other hand, properties of solidify concrete, the fast chloride particle infiltration test rapid movement test will use to screen the chloride arrangement of cement and qualities. However, the current test methods and norms for sulphate assault will use for this issue.

Varma et.al (2015) was aiming for maximum and effective value of compressive strength and durability of concrete within $10 \%$ of replacement, as $10 \%$ replacement was suggested in previous studies. Author partially replaced the Rice Husk ash content in cement by $0 \%, 5 \%, 6 \%, 7 \%, 8 \%, 9 \%$, as well as $10 \%$ with curing period of 28, 60, and of 90 days. The specimens were introduced to some sample of different concentrations of hydrochloric acid. It was concluded that $6 \%$ replacement of cement gave good compressive strength and effectively resist the attack of hydrochloric acid.

Pratheba et.al (2018) conducted an experimental investigation to study the effect on strength of concrete by using sugarcane bagasse ash with ordinary Portland cement. They studied the change 
in properties of concrete with replacement of cement content by $5 \%, 10 \%, 15 \%$, and $20 \%$ with sugarcane bagasse ash. They come to know that $15 \%$ replacement of cement showed advantages like increase in strength and workability. As the percent of bagasse ash increases the concrete becomes lightweight.

Ganesan et.al (2007) recorded the mechanical and physical properties of concrete in his paper. They investigated the water absorption test, compressive strength test, permeability, resistance against chloride ions. They concluded that $20 \%$ replacement of bagasse ash with OPC shows the positive results, this replacement also have some advantages like more early strength less permeability.

Ganesan et.al (2008) uses the rice husk ash which was made by burning the rice husk in boiler. This boiler burnt rice husk ash contains $87 \%$ of silica. They analyse the mineralogical, chemical, physical characteristic primarily. They also include water absorption test, chloride penetration test, compressive strength, and split tensile test. It is found that $30 \%$ replacement ash shows positive result.

Madhusudhan et.al (2018) adopted trial and error method regarding the water cement ratio. They identified that compressive strength, workability of concrete are close to the conventional concrete mix when cement is replaced by $10 \%$ of ash of sugarcane bagasse and fly ash may be interchanged partially to get properties close to traditional mix. They achieved these result by using OPC 43grade and M20 concrete mix.

R.Srinivasan et.al (2018) partially replaced the cement with sugarcane bagasse ash by $5 \%, 10 \%, 15 \%, 20 \%$, \& $25 \%$ by weight and tested after 7 and 28 days. They concluded that $10 \%$ replacement shows higher compressive strength, flexural strength, and tensile strength. It is found that replacement of bagasse ash gives more workability to the fresh concrete and lower the density of concrete. This waste can make light weight concrete.

Muhammad et.al (2015) replaced the content of Rice Husk Ash by $0 \%, 5 \%, 10 \%, 15 \%$, in concrete and test the specimen after 7, 14, 28 days of casting. For chemical attack the sample were introduced with sulphuric acid and hydrochloric acid. It is found that adding RHA rises the strength and durability property in case of sulphate and chloride attack

\section{III.CONCLUSION}

By studying above research papers it is observed that generally $10 \%$ to $15 \%$ replacement of ash shows increased results of strength. The SCBA shows greater slump compared to fly ash and rice husk ash. Most of the conclusions are made without considering reinforcements behaviour. The results are drawn on the basis of ideal concrete mix. Mainly studies are performed without considering actual sites condition. Most of the studies are done to find the compressive strength of the concrete, percentage of replacement, and cost reduction.

\section{REFERENCES}

[1] Vinny Pushkaran,ManjulaUnni, Nandana K, Nandakishore, Vilma, "Durability Studies of Sugarcane Bagasse Ash Concrete". IJIRSET (2017) vol. 6, 17301-17306.

[2] P. R. Wankhede, V. A. Fulari, "Effect of Fly ASH on Properties of Concrete". IJETAE (2014) vol. 4, 284-289.

[3] Siddamreddy Anil Kumar Reddy, Dr. K. Chandrasekhar Reddy, "Effect of Fly Ash on Strength and Durability Parameters of Concrete", IJSR (2015), VOL. 4, 1368-1370. 
[4] Nasir Shafiq, MuhdFadhilNuruddin, Asma AbdElhameed, "Effect of Sugar Cane Bagasse Ash (SCBA) on Sulphate Resistance of Concrete", IJERSTE (2014), 64-67.

[5] G. Nithin Kumar Reddy, G. HarshaVardhan, S. VijayaBhaskar Reddy, "Partial Replacement of Cement in Concrete with Sugarcane Bagasse Ash and its Behaviour in Aggressive Environments". IOSR-JMCE, (2016), 29-35.

[6] Divyadevi Sundaravadivel, Dr. R. Mohana, "Recent Studies of Sugarcane Bagasse Ash in Concrete and Mortar", IJERT (2018) vol 7, 306312.

[7] U. Dabai, Muhammad,U. Bagudo and Musa, "Studies on the Effect of Rice Husk Ash as Cement Admixture”, NJBAS (2009), 252-256.

[8] Seyed Alireza Zareeia, Farshad Amerib, Farzan Dorostkarc, Mojtaba Ahmadic, "Rice husk ash as a partial replacement of cement in high strength concrete containing micro silica: Evaluating durability and mechanical properties", ELSEVIER (2017), 73-81.

[9] Ayesha Siddika, Md. Abdullah Al Mamun, Md. Hedayet Ali, "Study on concrete with rice husk ash”, SPRINGER 2018.

[10] Badorul Hisham Abu Bakar, Ramadhansyah PutrajayaCand Hamidi Abdulaziz, "Malaysian Rice Husk Ash-Improving the Durabilityand Corrosion Resistance of Concrete: Pre-review", (2010) 6-13.

[11] P V Rambabu, J Gopala Varma, G V Ramarao, "Durability study on rice husk ash for optimum level of replacement of cement in concrete". IJETT (2015), Volume 28, 144-149.

[12] Pratheba.S, Deepeka.K, Kanimozhi.A, Malathi.J, Nandhini.J, "An experimental study on bagasse ash as partial replacement for cement in concrete”, IRJET (Mar-2018), Volume 05, 771774 .

[13] K. Ganesan, K. Rajagopal, K. Thangavel, "Evaluation of bagasse ash as supplementary cementitious material", ELSEVIER, Cement \& Concrete Composites 29 (2007), 515-524.

[14] K. Ganesan, K. Rajagopal, K. Thangavel, "Rice husk ash blended cement: Assessment of optimal level of replacement for strength and permeability properties of concrete, ELSEVIER, Construction and Building Materials", ELSEVIER, (2008)1675-1683.

[15] M.madhusudhan reddy, k.raja sekhar reddy, ss. Asadi, "A study on compressive strength of conventional concrete by replacing with fly ash and sugarcane ash", IJPAM (2018), volume 119, 1787-1791.

[16] R.Srinivasan, K.Sathiya, "Experimental Study on Bagasse Ash in Concrete", IJSLE 2018, vol. 5, 60-66.

[17] Muhammad Aleem, Istehsan-ur-Rahim, Umair Anwar Awan, Usman Afzal, Usman Haseeb, "Incorporation of Rice Husk Ash as Cement Replacement", IOSRJEN (July. 2015), Vol. 05, 25-30.

\section{Cite this article as :}

Nayan Kawaduji Mohankar, Shrikant Solanke, " Review on Effect of Fillers on Strength and Durability of Concrete", International Journal of Scientific Research in Science and Technology(IJSRST), Print ISSN : 2395-6011, Online ISSN : 2395-602X, Volume 7, Issue 3, pp.69-73, May-June-2020. Available at doi : https://doi.org/10.32628/IJSRST207315 Journal URL : http://ijsrst.com/IJSRST207315 